\title{
English for General Academic Purposes or English for Specific Purposes? Language Learning Needs of Medical Students at a Chinese University*
}

\author{
Yuehua Li \\ School of Foreign Languages, Xinxiang Medical University, Henan, China \\ Marion Heron \\ University of Surrey, Guildford, UK
}

\begin{abstract}
The debate over the appropriacy of EGAP and ESP has been an ongoing concern in many higher education contexts. In this paper we discuss how teachers' and students' perceptions of English curriculum needs are reflected in the conflict between short-term goals, such as passing exams, and long-term goals, such as career development. Students, doctors and teachers at a medical university in the central part of China were asked about their needs through questionnaires and structured interviews. The findings suggest that whilst many felt the need for medical English to be taught in the early years, particularly through medical texts, there was also push back due to the need for general English to pass English exams, such as CET4/6. We argue that through the incorporation of medical texts, students can start to develop their medical English from the first year of university. This not only ensures the motivation for students to study medical English for professional purposes, but also fulfills the perceived need to prepare for the exam.
\end{abstract}

Index Terms-EGAP, ESP, medical students, needs analysis, long-term goals, short-term goals

\section{INTRODUCTION}

In the context of the Belt and Road Initiative ${ }^{1}$ and the "Double-First Class" Initiative ${ }^{2}$, Chinese President Xi Jinping (2017) explicitly requires universities to "cultivate a large number of world-class scientists and technologists in strategically important fields, scientific and technological leaders, young scientists and engineers, as well as highperforming innovation teams" at the report of 19th National Congress of the Communist Party of China. It is clear that these people should have the ability to engage in professional study and research in English and the ability to exchange professional ideas and achievements in international academic seminars or in international professional journals. However, writing papers and exchanging research results in English has been the biggest challenge for Chinese researchers due to the fact that undergraduate education in China lacks such crucial training ('Turning Point: Chinese Science in Transition', 2015). It seems that higher education (HE) in China is faced with unprecedented challenges.

Since the Opening and Reform of China in 1978, "English education has not achieved success as expected because a whole generation of scientific and technological staff and engineering staff in China are unable to use English skilfully to absorb the information of their disciplines and industries, unable to use English for effective communication in research and work" (Cai, 2018, P12). Wen (2012) also states that the present HE English teaching is "high input and low effect" and "the shortage of high-level foreign language talents with international vision and Chinese vision has increased" (P283). Both researchers argue that the current HE English education cannot meet society's and students' needs.

Cai (2011) firmly believes that the general HE English teaching, EGAP (English for General Academic Purposes), should be replaced by ESP (English for Specific Purposes) since there is little difference between EGAP taught in HE and high school English. In contrast, many scholars believe that EGAP and ESP should complement each other (Wang \&Yao, 2013; Wen, 2014). This study aimed to examine to what extent the English curriculum satisfies the students'

\footnotetext{
* This work was supported by China Scholarship Council; Fund project: Henan Provincial Department of Education Humanities and social sciences research project "Chinese medical students' English learning needs analysis and Countermeasures". Project No.: 2020-ZDJH-341

${ }^{1}$ Belt and Road Initiative: short for the Silk Road Economic Belt and the 21st century Maritime Silk Road, is a development strategy adopted by the Chinese government in 2013 which aims to improve cooperation within the vibrant economies of Asia, Europe and Africa.

2 "Double-First Class" Initiative: Double First Class University Plan, which mainly contains the university list published by Chinese authorities in late September 2018 for developing a number of world-class universities and disciplines by the end of 2050 and improving China higher education power and international competitiveness.
} 
needs in terms of their studies and future careers and how EGAP and ESP can be balanced in the curriculum of a Chinese medical university.

\section{LITERATURE REVIEW}

\section{A. EGAP, ESP and EMP}

English is taught as a foreign language in China and EGAP is the mainstream in most universities and colleges. As Dudley-Evans and St John (1998) state, "EGAP refers to the teaching of the skills and language that are common to all disciplines; ESAP (English for Specific Academic Purposes) refers to the teaching of the features that distinguish one discipline from others" (P41). Furthermore, "English for specific purposes (ESP) refers to the teaching and learning of English as a second or foreign language where the goal of the learners is to use English in a particular domain" (Paltridge \& Starfield, 2013, P2). We argue that EGAP and ESP can coexist in the Chinese EFL context. However, we also contend there needs to be an appropriate balance to avoid low achievement and low motivation. As Liu (1996) points out: "One of the big changes in English learning in the future is likely to be the integration of other subjects rather than just learning English"(P4), thus, it is the right time for the HE English teaching to at least head in the direction of ESP.

In the context of medical studies, Ferguson. G (2013) states that "Language plays a significant role in most professions but perhaps nowhere more so than in medicine, where effective communication is widely recognized as important to clinical outcomes"(P243). Therefore, it is necessary for medical students in China to learn Medical English since they need to read medical journals to keep up to date with scientific research, learn about the latest advancements and share research results in international seminars.

English for Medical Purposes (EMP) research has mostly focused on the use of materials in language teaching, and doctor-patient communication. For example, Begoña Bellés Fortuño (2016) adopted corpus analysis tools to compare and contrast popular science articles (PSAs) and scientific research articles (RAs), and concluded that PSAs can be used as pedagogical material for the teaching of EMP. Begoña Bellés Fortuño (2018) explored the use of multimodal texts in teaching EMP. Communication skills as part of EMP are crucial, as one study has shown that limited English proficiency is a barrier to medical comprehension and increases the risk of adverse medication reactions in patients (Wilson, Chen, Grumbach, Wang and Fernandez, 2005). A further study explored the effect of Medical English on students' general English proficiency and found that ESP instructions can significantly improve learners' overall linguistic competence (Kooroghli, Sajjadi and Rahimic, 2018).

\section{B. Needs Analysis}

West (1994) states that needs analysis involves both the end purpose of learners in the target situation and the process of learning. Hutchinson and Waters (1987) put forward a learning-centered approach, including both target needs and learning needs. Dudley-Evans and St John (1998) devised a model of needs analysis, including seven elements (professional information about learners, personal information about learners, language information about target situations, learners' lack, language learning needs, how to communicate in the target situation and learners' needs from the course), which is considered to be the most comprehensive theory in foreign language needs analysis (Chen, 2009).

In China, in a general English context, scholars have put forward theoretical frameworks for needs analysis, including situation analysis, learning goals analysis and occupational needs analysis (Xia \& Kong, 1999) and social and students' needs (Shu, 2004). A comprehensive model, widely used in the Chinese context, has been suggested by Chen (2010). There has also been a body of empirical research into needs analysis. Zhao, Lei and Zhang (2009) found that on the whole students' English learning needs are disparate. In contrast, Wang and Liu (2003) found that students' learning needs are homogeneous. Cai (2012), through a needs analysis of four universities found that in the context of internationalization of higher education, students' demand for learning Academic English is urgent. Wang and Wang (2011) conducted a comprehensive survey on English teaching in 530 Chinese universities and concluded that a complete English curriculum system should include EGAP, ESP and English for General Education.

Research into medical students' language needs across the globe has found that the four skills of reading, writing, speaking and listening are the main requirements. Vahdany and Gerivani (2016) demonstrated that in an EFL context in Iran both medical students and General Practitioners valued reading skills the most, with speaking being the least important for both groups. Gaffas (2019) found that in an EFL context in Saudi Arabia a lack of rich L2 vocabulary was students' greatest difficulty and this negatively impacted their performance in all four English skills. Kayaoğlu and Dağ Akbaş (2016) indicated that in an EFL context in Turkey students' priorities in learning English were to be able to interact with others and achieve a high score in the language exam. Suitable and appropriate in-house teaching materials are crucial to address ESP learners' specific academic needs, as is the development of appropriate speaking and reading skills (Javid \& Umer, 2013).

In the Chinese context, $\mathrm{Xu}$, Xiao and Ling (2006) found that the majority of doctoral students need professional English reading and writing skills, while the majority of master students need professional English speaking, reading and writing skills. Chia, Johnson, Chia and Olive (1999) conducted a questionnaire survey on medical students' needs in Taiwan and found that listening is the most needed skill in a General English course and reading is the most important skill needed in Medical studies. Moreover, the majority of respondents perceived the present pattern of 
English courses - General English in the freshman year followed by three years of specific elective English - to be the most desirable. Hwang and Lin (2010) found out that reading was ranked the most important skill for medical students, while both students and teachers believed that the materials in the English course should be relevant to the medical field. Wang, Cai and Pang (2012) carried out a questionnaire survey among medical students in Anhui Medical University and found that EGAP can no longer meet their needs and the core of HE English curriculum in medical schools should shift to ESP in the future.

This study focuses on the following research questions:

1. What are the medical students' difficulties and goals of learning English at a Chinese Medical University?

2. What are the medical students' perspectives of the current textbook and curriculum?

3. Are there any differences between the freshmen and juniors' perspectives?

4. What are the English language needs of doctors and teachers for their research and work?

5. What do doctors and teachers think of the current English curriculum at X University?

\section{MethodOLOGY}

The study was carried out at a medical university in the central part of China (henceforth X University) focusing on the five-year undergraduate program where the English course offered for freshmen and sophomores is EGAP, and for juniors ESP. No English course is offered during the fourth year and the fifth year. Medical students at the X University are encouraged to pass the College English Test Band 4 and Band 6 (CET4/6), which is a national English level test, during the first two years at university, and then take part in the Unified National Graduate Entrance Examination(UNGEE) during the fifth year. The UNGEE comprises a preliminary examination, including two exams in specialized courses, one exam in politics and one exam in a foreign language (usually English), and a reexamination. Those who meet the preliminary exam score requirements are eligible for the reexamination. The reexamination, organized by admission institutions themselves, includes a written test and an interview (usually in English). The content of both the CET4/6 and the English exam of the UNGEE is EGAP. However, medical students are also required to develop competence in Medical English for their content studies and careers as doctors. Thus, there exists a conflict between short-term instrumental goals of passing national exams based on EGAP, and the professional goals of proficiency in Medical English. This study aimed to surface these conflicting goals from both students', doctors' and teachers' perspectives. It is important to understand both the general perspective of the participants, as well as their individual experiences. For this reason, a mixed-methods approach was taken as it "combines elements of qualitative and quantitative research approaches for the broad purpose of breadth and depth of understanding and corroboration" (Copland, Garton \& Burns, 2013, P741).

\section{A. Participants}

The participants involved in this survey were categorized into three different groups (see Table1): freshmen, juniors and doctors/ teachers. The third group includes doctors from the three affiliated hospitals of X University and teachers from X University. Both the doctors and teachers teach medical subjects at X University. The doctors and teachers, whose age ranges from 26 to 50, were put into one group because they had previously been medical students and therefore are clearly familiar with the English language needs of medical students. Both freshmen and juniors answered the same questionnaire for students as the purpose was to explore the differences between freshmen's and juniors' needs. In total, 23 doctors and teachers answered the questionnaire for doctors/teachers. Ten participants from each group participated in the interviews.

TABLE 1

QUESTIONNAIRE: THREE GROUPS OF PARTICIPANTS

\begin{tabular}{|l|l|l|}
\hline Group & Number & Study \\
\hline Freshman & $346(134$ males, 212 females $)$ & EGAP \\
\hline Juniors & 299 (98 males, 201 females $)$ & ESP \\
\hline Doctors / teachers & 23 (15 males, 8 females $)$ & $39 \%$ PhDs, 52\% Masters \\
\hline
\end{tabular}

\section{B. Methods}

\section{Questionnaires}

A questionnaire comprising 13 questions was designed to explore students' perceived language needs. In addition, a second questionnaire comprising 13 items was developed for doctors and teachers which focused on their professional needs of English language.

Both questionnaires were designed according to Chen's (2010) College English needs analysis model, which includes two sub-models: the analysis model of students' needs and the analysis model of social needs. The analysis model of students' needs, which was mainly based on Dudley-Evans and St John's (1998) needs analysis model, is composed of four dimensions, and the analysis model of social needs is also composed of four dimensions (see Table2). 
TABLE 2

HE ENGLISH NeEdS ANALYSis Model (CHEN, 2010, P121-122, BASED ON DUdLEY-EVANS AND ST JOHN, 1998)

\begin{tabular}{|l|l|}
\hline The analysis model of students' needs & The analysis model of social needs \\
\hline $\begin{array}{l}\text { Learning ability gap (including personal basic information, self- } \\
\text { evaluation of English skills and difficulties in English learning) }\end{array}$ & Basic information \\
\hline $\begin{array}{l}\text { Learner individual desire (including desire to improve English skills, } \\
\text { purpose of learning English) }\end{array}$ & $\begin{array}{l}\text { Use of English at work (including the importance of English at work, } \\
\text { the frequency of using English at work) }\end{array}$ \\
\hline $\begin{array}{l}\text { Learning process demand (including the frequency of using learning } \\
\text { strategies, self-evaluation of learning interests and attitudes, and } \\
\text { methods of learning English skills) }\end{array}$ & $\begin{array}{l}\text { Self-evaluation of English proficiency (including satisfaction with } \\
\text { English skills and difficulties in English) }\end{array}$ \\
\hline $\begin{array}{l}\text { Learning environment demand (students' demand for English } \\
\text { teachers, students' needs for in-class environment, students' needs } \\
\text { for an extracurricular environment, students' demand for textbooks } \\
\text { and learning resources, students' demand for class time and students' } \\
\text { demand for assessment methods) }\end{array}$ & $\begin{array}{l}\text { The applicability of college English teaching to social needs } \\
\text { including English proficiency requirements for the current position, } \\
\text { the of CET-4 and CET-6 on employment and work, and the }\end{array}$ \\
\hline
\end{tabular}

The two questionnaires employed a 5-point Likert scale ranging from 1 (total disagreement) to 5 (total agreement). Both freshmen and juniors were asked to complete the questionnaire for students online during the intervals of their English class, and it took them about 10 minutes. The doctors and teachers answered the questionnaire for doctors/teachers online when they were available.

2. Interviews

Structured interviews were conducted with ten participants from each of the three groups respectively. They were randomly selected from study participants. All the participants were assured that the data would only be used for this research, their names would be pseudonymous, and all the recorded data would be deleted after the study. The interview questions (see Appendix) reflected the questionnaire items. Eight interview questions were posed to freshmen and juniors and five questions were posed to doctors /teachers. Interviews with freshmen and juniors were conducted after class on campus and it took each about 20 to 30 minutes since all the questions had been given to the participants beforehand. The interviews with doctors/teachers were conducted in their offices and it took about 20 minutes each. All interviews were recorded and subsequently transcribed verbatim (Rapley, 2007) by the first author.

\section{Data Analysis}

The data were collected between May and August 2019. The data obtained by questionnaires was analyzed through SPSS Statistics 26 to generate the descriptive statistics---means, standard deviations and percentages. Independentsample T-test was applied to identify any difference that was calculated at (0.05) level of significance between freshmen and juniors.

The interview transcripts were analyzed thematically (Braun \& Clarke, 2006) focusing on the research questions, and, identifying perceived language needs. The data were allocated to codes and stored in NVivo12. The codes were then organized into four main themes: challenges, goals, perspectives on learning materials, perspectives on EGAP and ESP.

\section{FINDINGS}

\section{A. Quantitative Results: Students}

The table below outlines students' perceptions of their curriculum needs in learning English at X University. The results of the questionnaire for medical students show medical students' difficulties and purposes in learning English, and their perspectives of their English proficiency, textbook content and curriculum. 
TABLE 3

RESUlTS OF THE QUESTIONNAIRE FOR MEDICAL STUDENTS

\begin{tabular}{|c|c|c|c|c|}
\hline Questionnaire item & Group & Number & Mean & SD \\
\hline \multirow[t]{2}{*}{ 1. My biggest problem of learning English is listening and speaking. } & Freshmen & 346 & 4.33 & .920 \\
\hline & Juniors & 299 & 4.39 & .849 \\
\hline \multirow[t]{2}{*}{ 2. My biggest problem of learning English is vocabulary and grammar. } & Freshmen & 346 & 3.98 & .896 \\
\hline & Juniors & 299 & 3.98 & .945 \\
\hline \multirow{2}{*}{$\begin{array}{l}\text { 3. My purpose of learning English is to pass CET4/6 and the English exam of the } \\
\text { UNGEE. }\end{array}$} & Freshmen & 346 & 3.72 & 1.098 \\
\hline & Juniors & 299 & 3.73 & 1.115 \\
\hline \multirow[t]{2}{*}{ 4. My purpose of learning English is to go abroad. } & Freshmen & 346 & 2.86 & .979 \\
\hline & Juniors & 299 & 2.71 & .985 \\
\hline \multirow[t]{2}{*}{ 5. My purpose of learning English is to get a good job. } & Freshmen & 346 & 3.82 & .981 \\
\hline & Juniors & 299 & 3.94 & .895 \\
\hline \multirow[t]{2}{*}{ 6. My English level has been improved in college. } & Freshmen & 346 & 2.69 & 1.061 \\
\hline & Juniors & 299 & 2.95 & 1.161 \\
\hline \multirow[t]{2}{*}{ 7. I think the textbooks we use contribute to the improvement of my English. } & Freshmen & 346 & 3.42 & 1.047 \\
\hline & Juniors & 299 & 3.41 & .967 \\
\hline \multirow[t]{2}{*}{ 8. I think college English textbooks should contain texts about Medical English. } & Freshmen & 346 & 3.98 & .793 \\
\hline & Juniors & 299 & 4.12 & .612 \\
\hline \multirow[t]{2}{*}{ 9. I think English learning should continue when we pass CET4 and CET6. } & Freshmen & 346 & 4.37 & .720 \\
\hline & Juniors & 299 & 4.34 & .744 \\
\hline \multirow{2}{*}{$\begin{array}{l}\text { 10. I hope the university can offer Medical English current news articles for reading } \\
\text { course for juniors and seniors. }\end{array}$} & Freshmen & 346 & 4.18 & .777 \\
\hline & Juniors & 299 & 4.02 & .906 \\
\hline \multirow{2}{*}{$\begin{array}{l}\text { 11. I hope the university can offer medical writing and translation course for juniors and } \\
\text { seniors. }\end{array}$} & Freshmen & 346 & 4.05 & .875 \\
\hline & Juniors & 299 & 3.97 & .974 \\
\hline \multirow{2}{*}{$\begin{array}{l}\text { 12. I hope the university can offer Medical English listening and speaking course for } \\
\text { juniors and seniors. }\end{array}$} & Freshmen & 346 & 4.08 & .858 \\
\hline & Juniors & 299 & 3.97 & .962 \\
\hline \multirow{2}{*}{$\begin{array}{l}\text { 13. I hope the university can offer British and American culture course and cross-cultural } \\
\text { communication course for juniors and seniors. }\end{array}$} & Freshmen & 346 & 4.07 & .842 \\
\hline & Juniors & 299 & 4.04 & .942 \\
\hline
\end{tabular}

As for the purpose of learning English, medical students are exam driven. This is clear in the results above (Q3). However, the results for Q5 indicate that many students learn English to find a good job. Q6 revealed significant differences in students' perspectives on the development of their English. The Independent T-test indicated significant differences between the two groups $(\mathrm{p}<0.05)$. It is clear that both freshmen and juniors are dissatisfied with the current HE English teaching curriculum, with freshman students demonstrating significant dissatisfaction. A possible explanation for this is that the role of English has changed from a core subject in high school to a relatively less important subject compared to medical subjects, which consequently encourages students to spend less time and attention on English.

In terms of textbooks, both freshmen and juniors thought that their present textbooks contribute to improving their English (Q7). Since they are medical students, they hoped to learn Medical English through medical texts earlier on in the curriculum $(\mathrm{Q} 8)$. The responses to medical texts were significantly different $(\mathrm{P}<0.05)$ between the two groups. The juniors showed more eagerness to incorporate medical texts in English from early years. A possible reason is that juniors have already learned Medical English for one semester, and they find it very useful but difficult to learn.

Although CET4/6 is not a requirement for students at X University, most of them still take it during the first two years as an indication of their English proficiency. The results for Q9 reveal that medical students fully acknowledge the importance of English for their study and future career and they want to continue to learn English after passing CET4/6. Since there is no English course offered to students in the final two years after the Medical English courses in the junior year, both freshmen and juniors showed great interest in Medical English courses. They would be motivated by Medical English courses which include a reading course that focused on current medical news articles, medical writing and translation, Medical English listening and speaking course, British and American culture course and crosscultural communication course (Q10, Q11, Q12 and Q13). The results also indicate that medical students want to further their Medical English in the final two years of study.

Regarding the curriculum (Q10), all three groups responded positively to the idea of a reading course on current medical news articles in English.

\section{B. Quantitative Results: Doctors / Teachers}

Results of questionnaire for doctors/teachers (Table 4) show their use of English at work, self-evaluation of English proficiency, goals in English and perspectives of English curriculum. 
TABLE 4

RESULTS OF QUESTIONNAIRE FOR DOCTORS AND TEACHERS

\begin{tabular}{|c|c|c|c|}
\hline Questionnaire item & Number & Mean & SD \\
\hline 1. I often read English books and journals to learn about the latest research in medical industry. & 23 & 4.09 & .949 \\
\hline 2. I use English in my research and paper writing. & 23 & 4.35 & .935 \\
\hline 3. My English satisfies my needs to read English magazines and write academic papers. & 23 & 3.57 & 1.037 \\
\hline 4. I can understand English speeches in international conferences. & 23 & 3.00 & 1.087 \\
\hline 5. What I want to improve most is my English reading and writing. & 23 & 3.70 & .926 \\
\hline 6. What I want to improve most is my English listening and speaking. & 23 & 4.70 & .470 \\
\hline 7. I hope to have a chance to go abroad to study or do medical research. & 23 & 4.61 & .583 \\
\hline 8. I think passing CET4 and CET6 is enough for doctor's and teachers' research and work. & 23 & 2.70 & 1.063 \\
\hline 9. I think medical students should learn Medical English after passing CET4 and CET6. & 23 & 4.09 & 1.083 \\
\hline 10. I think the present college English education can satisfy graduates' needs in work. & 23 & 2.83 & .887 \\
\hline 11. I think medical universities should offer Medical English listening and speaking course. & 23 & 4.26 & .964 \\
\hline 12 I think medical universities should offer Medical English current news for reading course. & 23 & 4.26 & .752 \\
\hline 13. I think medical universities should offer Medical English writing and translation course. & 23 & 4.35 & .885 \\
\hline
\end{tabular}

The results for Q1 and Q2 show doctors / teachers often read English books and journals to learn about the latest research in medical industry and they need to use English in doing research and writing papers. Q3 highlights the importance of the need to read professional texts in English, and Q4 shows the importance of understanding presentations in English at conferences. These responses emphasize the importance of English for professional purposes. Results for Q5 indicated that all the 23 participants (100\%) wanted to improve listening and speaking most. They also wanted to improve English reading and writing (Q5). In contrast to the medical students who were uncertain of going abroad, $96 \%$ of the doctors / teachers wanted to go abroad to study and do medical research (Q7).

Doctors /teachers believed that CET4/6 are inadequate for their research and work (Q8) and they showed their dissatisfaction with the present HE English education (Q10). They agree with medical students that medical students should learn Medical English after passing CET4/6(Q9). In terms of the college English curriculum, doctors / teachers also agree with medical students and think highly of Medical English courses for juniors and seniors (Q11, Q12 and Q13).

\section{Qualitative Results}

\section{Challenges in English}

The questionnaire data pointed to considerable challenges with listening and speaking skills. The results of thematic analysis revealed a range of challenges for medical students and doctors/ teachers in English. They encounter challenges with listening, speaking, reading, vocabulary, writing, translation, and grammar and struggle with syntax and pragmatics. For example, the student below commented on the difficulties of listening to long stretches of discourse.

(1) "My biggest problem is listening. I can understand sentence by sentence, but I cannot follow when listening to a whole passage."

Similarly, a doctor also commented on the challenges of listening.

(2) "My weakness is listening and speaking. I want to improve listening and speaking. But what I want to improve urgently is spoken English."

A teacher also found speaking to be an obstacle:

(3) "What is relatively difficult for me in the five skills is speaking."

As can be seen, the doctor focuses on the significance and urgency of developing spoken skills. This feeling is also reflected in student comments. In particular, a lack of confidence can also impede students' perception of their challenges:

(4) "My biggest obstacle at the moment is spoken English. My pronunciation is not correct, and I'm also embarrassed to speak."

Comments 1-4 above reveal the difficulties students, doctors /teachers face with listening and speaking, key oracy skills required for class work (Mercer, 1995). These skills are also crucial to academic achievement and successful employment (Heron, 2019). One of the possible reasons for these difficulties lies in the lack of opportunities for the participants to use English outside the EFL context.

In terms of vocabulary challenges, it is worth pointing out here that medical texts contain a large number of specialist terminology. Proficiency and understanding of disciplinary terminology has been linked to academic success (Basturkmen, 2018). For example, one student highlights this as a key restriction:

(5) "My biggest challenge in learning English at present is the limitation of my vocabulary."

A teacher focuses on the need for disciplinary vocabulary to access the medical journals, and in this way, the community of doctors / medics:

(6) "When I have vocabulary difficulty in reading English journals, I often use online dictionaries."

A doctor talks about the strategies he uses to overcome the challenge of his understanding:

(7) "When encountering new medical terms, at first I looked up the words one by one and found it was a waste of time. Then I read the whole sentence, trying to understand it." 
It is interesting to note that in (6) and (7), the teachers and doctors have found a way to manage their difficulties with vocabulary, such as consulting online dictionaries and getting the gist from the context. Teachers and doctors have had more experience with language learning, whereas students do not seem to have the same awareness of different learning strategies.

2. Goals of learning English

The results of the thematic analysis showed the goals of learning English include communication goals, going abroad, exam focus and career development.

In the interview, all the three groups showed their strong expectations for effective English communication. One student stated that he wants to speak fluent English with foreigners:

(8) "I have a very high expectation of myself. I always want to be able to communicate with foreigners fluently."

A teacher commented that English language is useless if it cannot be used:

(9) "I urgently need to improve my listening and speaking skills because English is useless if I can't use it."

And a doctor also showed his eagerness to improve his ability of communication in English through training:

(10) "If I get the opportunity to attend English training, I want to improve my listening, speaking and writing."

As can be seen, communication represents an urgent need for medical students and doctors/teachers.

As for going abroad, students who have plans to go abroad will make some language preparations like taking IELTS or TOFEL in university. For example:

(11) "I got an IELTS score of 6.5 ... I have plans of going abroad. I may further my postgraduate education abroad and hope to grasp the English language."

A very important goal of medical students is to pass exams. As we know from the questionnaire data, medical students are exam focused and the interview data confirms this finding. For example, when asked about their expectations of learning English a student said:

(12) "The most realistic is that I want to pass cet-4/6 and the English exam of the UNGEE."

In addition, medical students also need ESP for future career development. A student commented on the medical English:

(13) "It is necessary to take medical English course during the last two years since it can prepare us for future career and research."

As can be seen, passing exams is among medical students' short-term goals and career development is one of their long-term goals. Nonetheless, the English exams are based on EGAP and it is very difficult for medical students to balance EGAP and ESP at university.

3. Perspectives on learning materials

In China, students have fixed English textbooks and their perspectives of English textbooks represent a crucial part of their English language needs. The interview data revealed that medical students need both general English texts and Medical English texts.

A student expressed the general English textbook can broaden her horizons:

(14) "I like the current textbook, because it contains all kinds of texts. In the textbook we can not only learn English knowledge, but also expand the field of vision and learn some truth."

Another student showed that the general textbook is rich in content and he can learn about some foreign cultures:

(15) "The textbook is OK. There is always a lot about foreign cultures. It involves geography, history, humanities knowledge, etc."

The above two comments show that medical students need general English texts to stimulate their interest in English, broaden their horizons and expose them to foreign cultures.

On the other hand, as medical students they are also keen on medical texts and they hope to learn from Medical English texts earlier. A student said he hopes to combine English and the specialized courses:

(16) "I think it's good to have some medical texts in the textbook. In this way, English can be more related to specialized courses, and I think it is more conducive to the understanding of English and specialized courses."

Another student hoped to know the latest development in medical industry through medical texts:

(17) "I think we can add some texts about medicine, such as the new discovery of some medical scholars or some medical literature, because we are medical students."

But they worried about the difficulty level of the medical texts:

(18) "The medical texts should not be too difficult, too esoteric."

A doctor also suggested that the medical texts should be less difficult and more interesting:

(19) "And I hope the university can offer Medical English from easy to more difficult. Because the current Medical English textbook for juniors describes a disease in a very long text, which is difficult to learn and less interesting."

As can be seen, medical students need both general texts and medical texts, but they suggest they can learn Medical English from medical texts earlier than they currently do. The reading texts, however, need to progress from easy to more complex.

4. Perspectives on EGAP and ESP

In the interview, medical students and doctors/ teachers showed different perspectives on the functions of EGAP and ESP. 
Some Medical students pointed out the problems of EGAP. A student said it only caters for average students:

(20) "General college English benefits the average students but I don't think it's really useful for me since I've already got an IELTS score of 6.5."

Another student pointedly pointed out that EGAP hinders students' English learning:

(21) "But the truth is the general English during the first two years are relatively easy and the exams are not so challenging. A lot of students are eating high school English capital."

As can be seen, EGAP is criticized among medical students because they cannot get much from it, which might be one of the reasons that medical students don't think their English is improved in university. Thus, a student suggested that ESP should be learned from the first year:

(22) "I think we should start to learn professional English from the first year, ... I think even at the level of high school English we can also understand professional English."

As for the importance of EGAP and ESP, Medical students and doctors/teachers also show different perspectives. Two students showed that EGAP is more important during undergraduate years:

(23) "I think general English is more important in undergraduate years and Medical English will be more important in postgraduate stage."

(24) "Because of the UNGEE exam, at this stage I think general English is more important."

However, some medical students and doctors/teachers suggest that ESP is more important. A student noted that she is more motivated to learn ESP:

(25) "I'm not impressed with general English. But I think Medical English is closely related with my major and I learn it with great momentum."

A teacher also believed that ESP is more important:

(26) "I think Medical English is more important."

A doctor suggested that EGAP and ESP complement each other:

(27) "General English is relatively more important in life, and Medical English is more important in work. They complement each other and are very important to me."

As can be seen, EGAP teaching, which has long been designed for the CET4/6 exam, is widely criticized by medical students and it is not appropriate for EGAP to predominate over ESP at a medical university.

\section{Discussion}

This paper has explored the perspectives of undergraduate medical students' English language needs for their medical education, and the doctors and teachers' professional needs of English language in their research and work. These needs have been identified according to the challenges faced in learning and using English and the participants' perspectives on language learning goals and learning materials. What has become apparent is the conflict and tension faced by students between short-term goals and long-term goals. In this section we outline the main findings and discuss the key issues.

The first key finding is that medical students have great difficulties in listening and speaking, and they urgently want to improve the skills of listening and speaking, which is consistent with the findings of Chia, et al. (1999) and Kayaoğlu and Dağ Akbaş (2016). The skills of listening and speaking are neglected during high school because they are not required in the College Entrance Examination. However, at university medical students start to realize the importance of oral/ aural skills since they are encouraged to develop their listening and speaking abilities in a free and relaxing atmosphere.

The second key finding is that there is a conflict between medical students' short-term goals, i.e. passing exams, and long-term goals, i.e. career development. During the five-year undergraduate program, medical students usually take two comprehensive English exams: CET4/6 and the English exam of the UNGEE. CET4/6, a national proficiency test, although widely criticized for many years, is still taken as a symbol of college English proficiency. The English exam of the UNGEE, a major challenge for medical students, to a great extent decides the admission to a good or ordinary university or even failure. That means medical students will put a lot of time and energy into learning English. As the content of the exams is EGAP, medical students spend most of their time on the five basic skills (listening, speaking, reading, writing and translating) in order to achieve success in the exam. Conversely, there is little time spent on ESP although ESP can better motivate them to learn English and it is very important for their future study and career. On the other hand, as medical students, they have to master medical terms and medical vocabulary in English. Furthermore, Medical English is also necessary if they want to become medical academics or professors in the future.

Thirdly, medical students want to learn ESP through medical texts from the first year, confirming the findings of Chia, et al. (1999) and Hwang and Lin (2010). With the fast development of the Chinese economy and the promotion of full Opening and Reform, many medical students especially those from big cities enter university with high English proficiency since they start to learn English at an early age. Therefore, they hope to learn English integrated into the medical subjects at university because they think the present EGAP teaching is not challenging enough and they find it less motivating.

Fourthly, the results indicate that there is no difference between freshmen and juniors' perspectives on the challenges and goals of learning English. Both freshmen and juniors demonstrate dissatisfaction with the HE English curriculum, 
with freshmen students citing significant dissatisfaction. Similarly, both freshmen and juniors hope to learn Medical English through medical texts with juniors showing more eagerness to learn from medical texts from the beginning of their HE studies.

Finally, about their professional needs, doctors and teachers, like undergraduate medical students, have great difficulty in listening and speaking. They have a strong desire to communicate with people in English, and they really want to seek a chance to go abroad to do research. They think junior and senior medical students should learn Medical English well after passing CET4/6 since Medical English plays a very important role in their research and work.

\section{CONCLUSION}

This study has explored the English language needs of undergraduate medical students from both students' perspectives and doctors/teachers' perspectives. A clear tension exists between short-term goals and long-term careeroriented goals. To bridge this gap, we have suggested a number of recommendations below. Since teaching EGAP predominates over ESP at X University, and a critical stance towards EGAP is emerging, we argue it is both timely and relevant to reconsider the balance of English language learning and teaching goals and to incorporate more English medical texts into the curriculum as a basis for ESP work.

A number of recommendations have emerged from this study.

- In terms of the curriculum, we argue that Medical English should be offered throughout the five-year undergraduate program with an increasing level of difficulty. It is recommended that a required course, which is a combination of EGAP and ESP in the first two years, and a required ESP course in the junior year be offered. Furthermore, it is argued that in the final two years elective English courses that involve reading current medical news articles, medical listening and speaking, medical writing and translation, medical research paper reading, British and American culture, and cross-cultural communication be offered.

- In terms of learning materials, it is suggested that there should be a balance of medical texts and general English texts included in the textbooks for freshmen and sophomores, so that medical students can start to learn Medical English from the first year, which will not only arouse students' interests and extend their horizons but also motivate them to learn Medical English. According to Bloor and Bloor (1986), teaching a specific variety of English (ESP) can start at any level including beginners. Our findings highlight the fact that it is feasible for medical students to start to learn ESP from the first year.

- Finally, communication with key stakeholders is essential. Doctors and teachers can be encouraged to share their experiences and English learning needs with students to highlight the variety of different purposes English serves in both academic studies and professional life.

\section{APPENDIX}

\section{Interviews with freshmen and juniors:}

1. Please express your views on general English or/and medical English respectively?

2. What is your biggest problem of learning English?

3. What is your expectation of learning English?

4. What do you think of the content in your textbook? What if there are some medical texts in your textbook during the first two years?

5. Do you think it is necessary to offer English courses for the five years successively?

6. What is your opinion if medical English courses are offered in the final two years in college?

7. What is your expectation about English teachers?

8. What is your ideal English class like?

Interview with doctors /teachers

1. When do you use English? Do you think medical English plays an important role in your work?

2. Do you have any difficulty when reading medical journals? If yes, what are the difficulties? And how do you deal with them?

3. What is your weakness in the five skills? If you get a chance to accept English training, which ability do you want to improve most?

4. In your daily life and work, general English and medical English, which one is more important?

5. If you go back to college, how would you like your English courses offered?

\section{ACKNOWLEDGMENTS}

The authors are grateful to the participants at X University for their participation in the project and to Dr Kieran Balloo from the University of Surrey for his help in the SPSS analysis and thematic analysis. 


\section{REFERENCES}

[1] Basturkmen, H. (2018). Dealing with language issues during subject teaching in EMI: The Perspectives of two Accounting lecturers. TESOL Quarterly, 52(3), 692-700.

[2] Begoña Bellés Fortuño (2016). Popular Science Articles vs Scientific Articles: A Tool for Medical Education. In OrdoñezLopez, P.\& Edo-Marza, N. (Eds) Medical Discourse in Professional, Academic and Popular Settings. Bristol: Multilingual Matters, 55-75.

[3] Begoña Bellés Fortuño (2018). Multimodality in medicine: How university medical students approach informative leaflets. System. 77, 28-38.

[4] Bloor, M., \& Bloor, T. (1986). Language for specific purposes: Practice and theory (occasional paper no. 19). Dublin: Trinity College.

[5] Braun, V., \& Clarke, V. (2006). Using thematic analysis in psychology. Qualitative Research in Psychology, 3(2), 77-101.

[6] Cai, J. (2011). About college English curriculum setting and teaching objectives -- and also about college English curriculum setting in Hong Kong. Foreign Language Teaching and Research, 43(4), 609-617.

[7] Cai, J. (2012). Needs analysis and teaching method research of "academic English" course. Foreign Language Teaching and Practice, 2, 30-35.

[8] Cai, J. (2018). Exploration on the paradigm of English as a second language teaching in "foreign language environment" -review and reflection on foreign language education in Chinese colleges and universities on the $40^{\text {th }}$ anniversary of Opening and Reform. Journal of Northeast Normal University (Philosophy and Social Sciences), 5, 12-17.

[9] Chen, B. (2009). A Critical Review of Needs Analysis Studies in Foreign Language Teaching Abroad. Foreign Language Teaching and Research, 41(2), 125-130.

[10] Chen, B. (2010). Theoretical Construction of College English Needs Analysis Model. Foreign Language Research, 2 , $120-123$.

[11] Chia, H.-U., Johnson, R., Chia, h.l., \& Olive, F. (1999). English for college students in Taiwan: A study of perceptions of English needs in a medical context. English for Specific Purposes, 18(2), 107-119.

[12] Copland, F., Garton, S., \& Burns, A. (2013). Challenges in teaching English to young learners: Global perspectives and local realities. TESOL Quarterly, 48(4). 738-762.

[13] Dudley-Evans, T., \& St John. M. J. (1998). Developments in English f or Specific Purposes: A Multi-disciplinary Approach. Cambridge: CUP.

[14] Ferguson. G (2013).English for Medical Purposes. In Paltridge, B., \& Starfield, S. (Eds.), The Handbook of English for Specific Purposes. London: Wiley-Blackwell, 243.

[15] Gaffas, Z. M. (2019). Students' perceptions of the impact of EGP and ESP courses on their English language development: voices from Saudi Arabia. Journal of English for Academic Purposes, 42, 100797.

[16] Heron, M. (2019) Making the case for oracy skills in higher education: practices and opportunities, Journal of University Teaching and Learning Practice, 16(2), 1-16.

[17] Hutchinson, T., \& Water, A. (1987). English for Specific Purposes-- a Learning-centered Approach. Cambridge: CUP.

[18] Hwang, Y., \& Lin, S. (2010). A study of medical students' linguistic needs in Taiwan. The Asian ESP Journal. Spring Edition, $6(1) .35-58$.

[19] Javid, C. Z., \& Umer, M. (2013). Investigating English language Needs: Medical Undergraduates Perspective in a Saudi Context. Pakistan Journal of Social Sciences, 33(2), 363-377.

[20] Kayaoğlu, M. N. \& Dă̆ Akbaş, R. (2016). An Investigation into Medical Students’ English Language Needs. Participatory Educational Research. Special Issue 2016-I, 63-71.

[21] Kooroghli, M. R., Sajjadi, S., \& Rahimi, F. (2018). Effect of Medical English on Students' General English Proficiency. The Asian ESP Journal. 14(4), 54-61

[22] Liu, R. (1996). English language teaching in the $21^{\text {st }}$ century--- Notes on the report from "English 2000". Foreign language teaching and research, 2, 1-8

[23] Mercer, N. (1995). The guided construction of knowledge: Talk amongst teachers and learners. Clevedon: Multilingual Matters.

[24] Nature. (2015). Turning Point: Chinese Science in Transition https://www.nature.com/press_releases/turning_point_cn.pdf (accessed 15/1/2019).

[25] Paltridge, B., \& Starfield, S. (2013). (Ed) The Handbook of English for Specific Purposes. London: Wiley-Blackwell.

[26] Rapley (2007). Doing Conversation, Discourse and Document Analysis. International Journal of Market Research 51(3), 428429.

[27] Shu, D. (2004). Foreign Language Teaching Reform: Problems and Countermeasures. Shanghai: Shanghai Foreign Language Education Press.

[28] Vahdany, F., \& Gerivani, L. (2016). An Analysis of the English Language Needs of Medical Students and General Practitioners: A Case Study of Guilan University of Medical Sciences, International Journal of English Language and Literature Studies, 5(2), 104-110.

[29] Wang, Y., Cai, Y. \& Pang, W. (2012). Analysis of Medical Students' Satisfaction and Needs for English Learning and the Countermeasures. Journal of Hefei University (Social Sciences), 29(3), 127-130.

[30] Wang, B. \& Liu, H. (2003). A survey on the learning needs of college English learners and its implications. Foreign Language Teaching Abroad, 3, 34-38.

[31] Wang, S. \& Yao, C. (2013). Some Thoughts on English for Academic Purposes (EAP) Teaching. Foreign Languages in China, 10(5), 4-10.

[32] Wang, S. \& Wang, H. (2011). On the State of College English Teaching in China and Its Future Development. Foreign Languages in China. 8(5), 4-12.

[33] Wen, Q. (2012). Challenges and countermeasures of college English: from the perspective of curriculum theory. Foreign Language Teaching and Research, 44(2), 283-292. 
[34] Wen, Q. (2014). The dispute between general English and special English in college English teaching: problems and countermeasures. Foreign Languages and Foreign Language Teaching, 1, 1-8.

[35] West. R. (1994). Needs analysis in language teaching. Language teaching, 27(1), 1-19.

[36] Wilson, E., Chen, A., Grumbach, K., Wang, F., \& Fernandez, A. (2005). Effects of Limited English Proficiency and Physician Language on Health Care Comprehension. Journal of General Internal Medicine. 20(9), 800-806.

[37] Xi, J. (2017). Secure Decisive Victory in Building a Moderately Prosperous Society in All Respects and Strive for the Great Success of Socialism with Chinese Characteristics for a New Era---Report at $19^{\text {th }}$ CPC National Congress. http://www.xinhuanet.com/english/download/Xi_Jinping's_report_at_19th_CPC_National_Congress.pdf (accessed 8/1/2020).

[38] Xia, J. \& Kong, X. (1999). A Probe into the Scientific Nature of Foreign Language Course Design. Foreign Language World, 1, $26-31$.

[39] Xu, J., Xiao, X., \& Ling, C. (2006). Need analysis of medical postgraduates' English language learning. China Higher Medical Education, 7, 33-34

[40] Zhao, Q., Lei, L., \& Zhang, M. (2009). College English teaching from the perspective of students' English learning needs. Foreign Language World, 4, 14-22.

Yuehua Li is a lecturer in the School of Foreign Languages at Xinxiang Medical University in China. Her research interests include second language acquisition and language teaching and learning.

Marion Heron is Senior Lecturer in Surrey Institute of Education, University of Surrey. Her research interests lie in the areas of educational linguistics and professional development. 